\title{
Coronavirus Disease 2019 (COVID-19) in Conakry, Republic of Guinea: Analysis and Relationship with Meteorological Factors
}

\author{
Ibrahima Kalil Kante ${ }^{1,2,3 *}$, Ibrahima Diouf ${ }^{1,4}$, Tamba Nicolas Millimono ${ }^{1,3,5}$, \\ Jean Moussa Kourouma ${ }^{2,6}$ \\ ${ }^{1}$ Laboratoire de Physique de l'Atmosphère et de l'Océan Siméon Fongang, École Supérieure Polytechnique, Université Cheikh \\ Anta Diop Dakar, Dakar, Senegal \\ ${ }^{2}$ Direction Nationale de la Météorologie de Guinée, Conakry, Guinea \\ ${ }^{3}$ Université Gamal Abdel Nasser de Conakry/Laboratoire d'Enseignement et de Recherche en Énergétique Appliquée de Conakry, \\ Conakry, Guinea \\ ${ }^{4}$ NOAA Center for Weather and Climate Prediction, College Park, Maryland, USA \\ ${ }^{5}$ Institut Supérieur des Sciences de l'Education de Guinée (ISSEG), Conakry, Guinea \\ ${ }^{6}$ Department of Plant and Environmental Science, School of Natural Resource, Copperbelt University, Kitwe, Zambia \\ Email: `ibrahima.kante@ucad.edu.sn
}

How to cite this paper: Kante, I.K., Diouf, I., Millimono, T.N. and Kourouma, J.M. (2021) Coronavirus Disease 2019 (COVID-19) in Conakry, Republic of Guinea: Analysis and Relationship with Meteorological Factors. Atmospheric and Climate Sciences, 11, 302-323.

https://doi.org/10.4236/acs.2021.112018

Received: February 8, 2021

Accepted: April 11, 2021

Published: April 14, 2021

Copyright $\odot 2021$ by author(s) and Scientific Research Publishing Inc. This work is licensed under the Creative Commons Attribution International License (CC BY 4.0).

http://creativecommons.org/licenses/by/4.0/

(c) (i) Open Access

\begin{abstract}
The coronavirus disease 2019 (COVID-19), caused by severe acute respiratory syndrome coronavirus 2 (SARS-CoV-2), dates back to December 29, 2019, in Wuhan, China. It quickly spreads like wildfire to all continents in the following months. In Guinea, the first case of COVID-19 and death were all reported respectively on March 12 and April 16, 2020. Since then, several studies have found a relationship between certain environmental conditions such as the meteorological factors to have the potential of contributing to the spread of the virus. Thus, this study aims at examining the extent to which observed meteorological factors might have contributed to the spread of the coronavirus disease 2019 (COVID-19) cases in Conakry, from March 1 to May 31, 2020. Meteorological factors such as temperature $\left(\mathrm{T}_{\min }, \mathrm{T}_{\text {mean }}\right.$ and $\left.\mathrm{T}_{\max }\right)$ and relative humidity $\left(\mathrm{RH}_{\text {min }}, \mathrm{RH}_{\text {mean }}\right.$ and $\left.\mathrm{RH}_{\text {max }}\right)$ were analyzed together with the data on the COVID-19. The dynamic of the COVID-19 in Guinea was analyzed along with that of some west African countries. The analysis on the dynamic of the COVID-19 pandemic in West Africa indicated Guinea as one of the most affected countries by the pandemic after Nigeria and Ghana. The study found that in general an increase in the temperature is linked to a decline in the COVID-19 number of cases and deaths, while an increase in the humidity is positively correlated to the number of cases and deaths. Nevertheless, from this study it was also observed that low temperature, mild di-
\end{abstract}


urnal temperature and high humidity are likely to favor its transmission. The study therefore, recommends that habitations and hospital rooms should be kept in relatively low humidity and relatively higher temperature to minimize the spread of the (SARS-CoV-2).

\section{Keywords}

Conakry, Guinea, COVID-19, Meteorological Factors, Temperature, Humidity

\section{Introduction}

In December 2019, pneumonia of an unknown cause was detected in Wuhan, China and reported to the World Health Organization (WHO, hereafter) country office in China. The outbreak was declared as a Public Health Emergency of International Concern (PHEIC), on January 30, 2020 and finally on February 11, 2020, considering the strain and the widespread of the disease worldwide, the world health organization (WHO) categorized the new disease as pandemic after naming it as Corona Virus Disease: COVID-19 (COVID-19, hereafter). Since then, several studies have been undertaken to understand the cause of the disease. Scholars such as [1] [2] [3] [4] indicated that COVID-19, was caused by a severe acute respiratory syndrome, coronavirus 2 (SARS-CoV-2). COVID-19 is an acute respiratory disease which may lead to pneumonia with symptoms such as fever, cough and dyspnea [5] and has an approximate fatality rate of $2 \%$ to $3 \%$ [6]. The SARS-CoV particle is represented in Figure 1 below COVID-19 belonging to the Coronaviridae family, Nidovirales order [7].

The COVID-19 has presented and confronted the world with huge challenges adding on the already unbearable existent ones. The world is currently in face of several crises due to the COVID-19, among others, the health crisis, education crisis, employment and economic crisis, crisis of hunger and poverty and, in some countries, a crisis of governance and political stability that need more coordinated efforts to overcome them.

For developing countries in Africa with much larger populations at risk, fewer resources and less coping capacity, the pressure to develop effective responses, and deliver them at scale is tremendous.

As countries strive to deal with the economic impacts and other challenges related to the management of the COVID-19 pandemic, there is an urgent need for new evidence and research to improve our understanding of the meteorological factors that might play a role of multiplier in the spread of the COVID-19 in order to provide appropriate policy responses. The COVID-19 has resulted in an ongoing pandemic after its spread to other continents and regions.

Consequently, COVID-19 has attracted the interest of scholars and researchers worldwide. However, the focus on the subject differed according to the discipline and research interest of the authors. First and foremost, the most important thing to determine by many was to confirm the human-to-human transmis- 
sibility of COVID-19 [8] [9]. Then from these researches, evidences were established on the way in which, the transmission happened (close contact, most often via small droplets produced during talking, sneezing or coughing). However, several containment measures have been recommended by the WHO to reduce the chances of infection, among others, the education on keeping the social distancing and wearing facemasks to prevent contact with body fluids and sneezing droplets.

From December to March 11, 2020, the WHO reported 118,319 confirmed cases and 4292 deaths worldwide [10] and declared as global pandemic on the same day [11]. On March 28, 2020, a total of 571,678 confirmed COVID-19 cases and 26,494 deaths have been reported worldwide [12]. In addition, on April 17, 2020 and as of April 24, 2020, 553,926 new cases of the coronavirus disease (in accordance with the applied case definition in the countries) have been reported, including 45,409 new deaths [13]. With the current trajectory of the COVID-19 outbreak, medical measures and public health will both be needed to contain the spread of the COVID-19 and to improve patient outcomes [7]. Figure 1 exhibits a representation of SARS-CoV particle [14]. COVID-19 belongs to the Coronaviridae family, Nidovirales order [7].

Figure 2 exhibits the history of coronavirus nomenclature during the three zoonotic outbreaks in relation to virus taxonomy and diseases caused by these viruses [2], by WHO. The Middle East Respiratory Syndrome (MERS) was discovered in 2012, followed thereafter by Severe Acute Respiratory Syndrome (SARS) in 2013. In December 2019, a virus with same characteristics was detected in Wuhan, China. Since the virus which was given the name of COVID-19 is reported to have been originated from wild animals, even though the precise

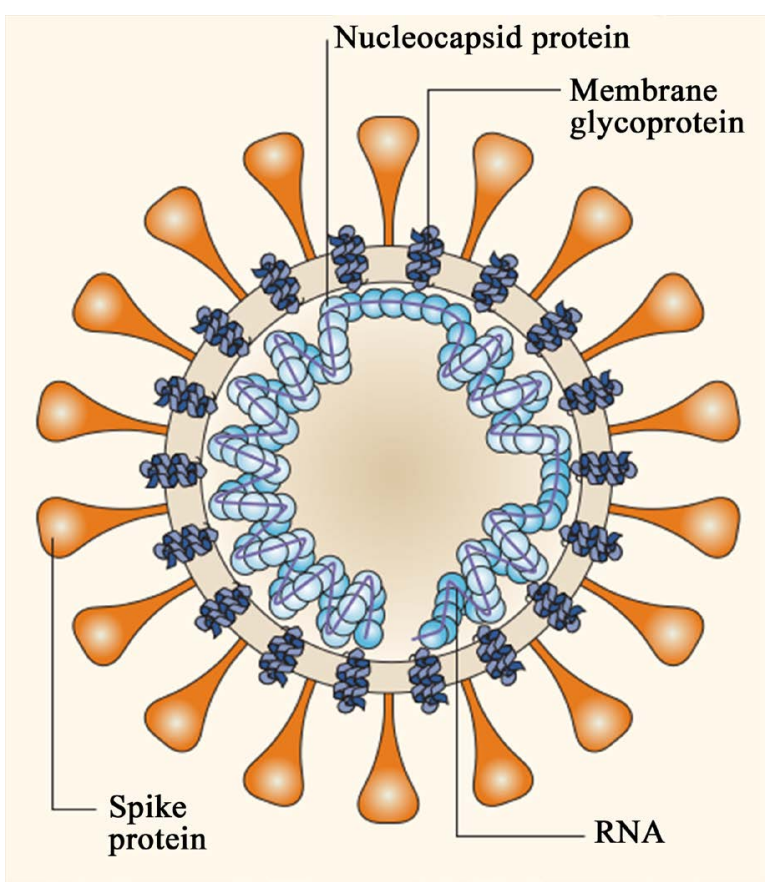

Figure 1. Representation of the severe acute respiratory syndrome coronavirus (SARS-CoV) particle [14]. 


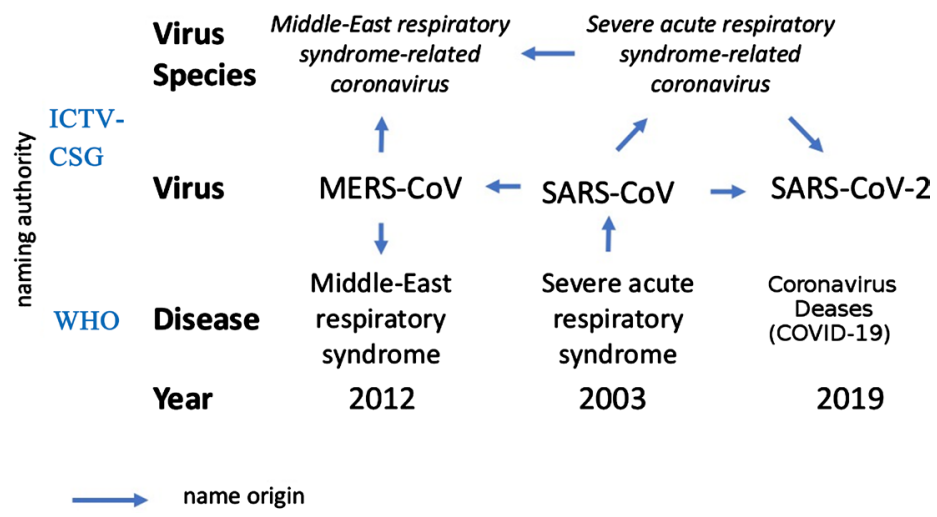

Figure 2. History of coronavirus naming in relationship to virus taxonomy and diseases caused by these viruses [2].

origin remains uncertain [15] [16].

\subsection{COVID-19 in West African Countries}

Since the outbreak of the COVID-19, it has rapidly evolved, affecting other parts of the world, and the sub-Saharan Africa. Researchers have striven to understand the patterns and dynamic of the virus, its transmission and impacts. Nigeria and Senegal were the west African countries to record the first confirmed cases of COVID-19 [7]. Guinea and Ivory Coast pronounced their first confirmed human cases of COVID-19 as the viral infection has now spread to at least 10 countries in West Africa [17] [18].

\subsection{COVID-19 in Conakry, Republic of Guinea}

According to the National Agency for Health Security (NAHS, hereafter) of Guinea, the first case of COVID-19 and death were recorded in Conakry, respectively on March 12, and March 16, 2020. By May 13, 2020, the COVID-19 confirmed cases in Guinea were totalling 5260, from which 4115 were declared recovered and the total number of deaths was as high as 29 . The total remaining active cases on the same date were 1076 (see Table 1).

Figure 3 exhibits the spatial distribution of confirmed cases of COVID-19 in the city of Conakry per day provided by the NAHS report of April 3, 2020. This figure explains the contagion range in percentage per commune of Conakry. It is Ratoma's council which has the highest percentage of contagion in Conakry with $51 \%$ up to now. Indeed, the main objective of this study is to analyze the COVID-19 evolution and its relationship to climate parameters such as temperature $\left(\mathrm{T}_{\min }\right.$, $\mathrm{T}_{\text {mean }}$ and $\left.\mathrm{T}_{\max }\right)$ and relative humidity $\left(\mathrm{RH}_{\min }, \mathrm{RH}_{\text {mean }}\right.$ and $\left.\mathrm{RH}_{\max }\right)$ in Conakry.

The transmission of viruses can be affected by many factors, including climate conditions, population density and medical care quality [19]. Weather conditions such as temperature and relative humidity can affect the transmission and virulence of viruses by impacting virus growth and host defense systems, and these effects have been studied extensively [20] [21] [22] [23]. It has been documented that the temperature and its variations might have affected the SARS 
Table 1. Reported cases and deaths by country, territory, or conveyance June 27, 2020 [27].

\begin{tabular}{|c|c|c|c|c|c|c|c|c|c|c|c|c|c|}
\hline All & Euro & & Nor & th Ameri & & Asia & South & America & $\underline{A f r}$ & ica & Ocean & & \\
\hline$\#$ & $\begin{array}{l}\text { Country, } \\
\text { Other }\end{array}$ & $\begin{array}{l}\text { Total } \\
\text { Cases }\end{array}$ & $\begin{array}{l}\text { New } \\
\text { Cases }\end{array}$ & $\begin{array}{c}\text { Total } \\
\text { Deaths }\end{array}$ & $\begin{array}{c}\text { New } \\
\text { Deaths }\end{array}$ & $\begin{array}{c}\text { Total } \\
\text { Recovered }\end{array}$ & $\begin{array}{l}\text { Active } \\
\text { Cases }\end{array}$ & $\begin{array}{l}\text { Serious, } \\
\text { Critical }\end{array}$ & $\begin{array}{c}\text { Tot Cases/ } \\
1 \mathrm{M} \text { pop }\end{array}$ & $\begin{array}{l}\text { Deaths/ } \\
1 \mathrm{M} \text { pop }\end{array}$ & $\begin{array}{l}\text { Total } \\
\text { Tests }\end{array}$ & $\begin{array}{l}\text { Tests/ } \\
1 \mathrm{M} \text { pop }\end{array}$ & Population \\
\hline & $\underline{\text { Africa }}$ & 366,090 & +3474 & 9438 & +121 & 177,365 & 179,287 & 904 & & & & & \\
\hline 1 & $\begin{array}{l}\text { South } \\
\text { Africa }\end{array}$ & 124,590 & & 2340 & & 64,111 & 58,139 & 539 & 2101 & 39 & $1,493,104$ & 25,180 & $59,297,807$ \\
\hline 2 & Egypt & 63,923 & +1168 & 2708 & +88 & 17,140 & 44,075 & 41 & 625 & 26 & 135,000 & 1320 & $102,299,983$ \\
\hline 3 & $\underline{\text { Nigeria }}$ & 23,298 & & 554 & & 8253 & 14,491 & 7 & 113 & 3 & 125,090 & 607 & $206,032,229$ \\
\hline 4 & Ghana & 16,431 & +597 & 103 & & 12,257 & 4071 & 6 & 529 & 3 & 286,453 & 9222 & $31,060,677$ \\
\hline 5 & Algeria & 12,968 & +283 & 892 & +7 & 9202 & 2874 & 48 & 296 & 20 & & & $43,837,260$ \\
\hline 6 & $\underline{\text { Cameroon }}$ & 12,592 & & 313 & & 10,100 & 2179 & 52 & 475 & 12 & & & $26,531,939$ \\
\hline 7 & $\underline{\text { Morocco }}$ & 11,877 & +244 & 220 & +2 & 8723 & 2934 & 7 & 322 & 6 & 633,494 & 17,166 & $36,904,364$ \\
\hline 8 & $\underline{\text { Sudan }}$ & 9257 & & 572 & & 4014 & 4671 & & 211 & 13 & 401 & 9 & $43,828,543$ \\
\hline 9 & $\underline{\text { Ivory Coast }}$ & 8739 & & 64 & & 3587 & 5088 & & 331 & 2 & 50,914 & 1,931 & $26,364,556$ \\
\hline 10 & $\underline{D R C}$ & 6690 & +138 & 153 & +4 & 937 & 5600 & & 75 & 2 & & & $89,495,791$ \\
\hline 11 & Senegal & 6459 & +105 & 102 & +4 & 4255 & 2102 & 26 & 386 & 6 & 76,303 & 4560 & $16,734,279$ \\
\hline 12 & Kenya & 5811 & +278 & & +4 & 1936 & 3734 & 18 & 180 & 3 & 162,478 & 3023 & $53,748,171$ \\
\hline 13 & Ethiopia & 5570 & +145 & 94 & +5 & 2015 & 3461 & 34 & 48 & 0.8 & 243,016 & 2115 & $114,903,773$ \\
\hline 14 & Guinea & 5260 & & 29 & & 4155 & 1076 & 24 & 401 & 2 & 14,407 & 1098 & $13,124,855$ \\
\hline
\end{tabular}

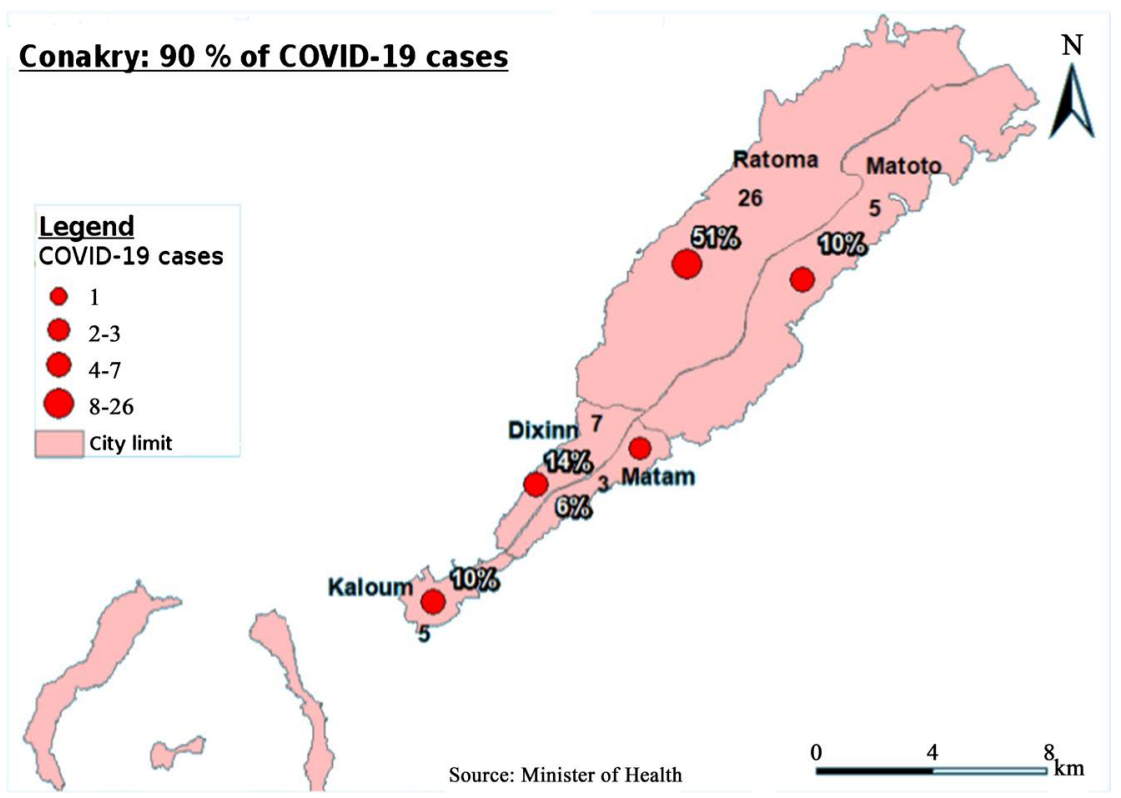

Figure 3. Spatial distribution of daily confirmed cases of COVID-19 in Conakry city according to the NAHS report on April 3rd, 2020 [26].

outbreaks [24]. Therefore, meteorological factors, such as ambient temperature and humidity, might play an important role in the spread of the disease [25].

Despite the fact, Guinea was along with Liberia and Sierra Leone, the three (3) 
countries of West Africa strongly affected by the Ebola virus disease resulting in 11,310 deaths out of 28,616 confirmed cases, very little study existed in Guinea pertaining to relationship between viral diseases in general and COVID-19 specifically with the climatic variables. Henceforth, this study aims to provide baseline information that may be of help in understanding the pattern of the virus transmission in relation to the climate in order to enable deciders and health specialists to provide adequate guidance to the public.

However, the relationship between viral diseases and climate behavior is less documented in our area of study (Conakry, Guinea) or nonexistent. It is in this context, that we performed an analysis by studying the COVID-19 pandemic in relationship to the climate in Guinea by considering the Conakry city. We use minimum, maximum and mean temperature and minimum, maximum and mean relative humidity as meteorological factors. This work is a novelty to research in Guinea and a major contribution to helping climate-health specialists understand the relationship between COVID-19 and the climate.

\section{Study Area}

This study was undertaken in Conakry, the capital city of Guinea (Figure 4). Conakry is located in the coast between both the Atlantic Ocean and the Kakoulima mountain at $9^{\circ} 34^{\prime} 36^{\prime \prime}$ latitude North, and $13^{\circ} 36^{\prime} 43^{\prime \prime}$ longitude West, with an altitude of $46 \mathrm{~m}$ above the sea level. Given that Conakry is a coastal zone that lies

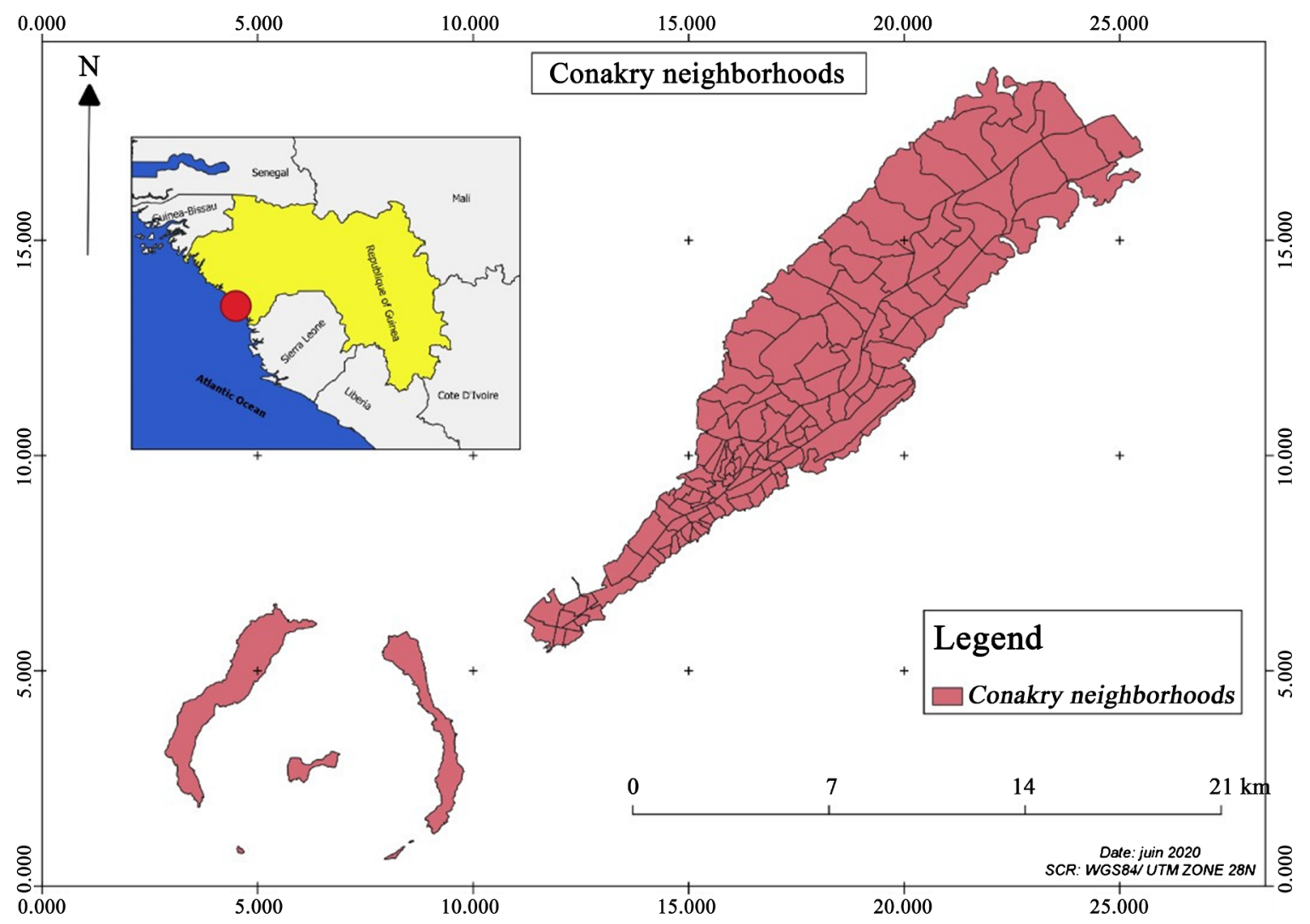

Figure 4. Location map of Conakry in Republic of Guinea. 
between the Atlantic Ocean and the Kakoulima Mountain range, which forms a barrier and promotes the Foehn phenomenon [28]. Foehn is a warm dry wind blowing upstream of a mountain and cools off overcoming this one. It can be favorable to the initiation of convection.

After the cases of COVID-19 skyrocketed, showing that it was no longer possible to contain the spread of the disease, the governments of many countries launched mitigation strategies, trying to slow down or contain the spread of the epidemic and flatten its curve [20]. This is explained by the rapid response of the government through the NAHS to very quickly confined Conakry, in order to control and mitigate the spread of the virus across the country.

\section{Data Acquisition and Method}

\subsection{Data Acquisition}

The climatic data used in this study were obtained from the National Meteorological Service of Guinea (NMSG). Observed meteorological factors such as temperature and relative humidity from March 1 to May 31, 2020 were considered. The location of this synoptic station at the international airport of Conakry makes the data set uninterrupted and of good quality.

The COVID-19 data used were obtained from the European Center for Disease Prevention and Control (ECDC), official website [29]. The downloadable data file is updated daily and contains the latest available public data on COVID-19. Each row/entry contains the number of new cases reported per day and per country. The data concern the cases recorded every day including: the number of new cases of COVID-19 confirmed by NAHS; the number of deaths and the number of recovering cases.

\subsection{Method}

Our study focused on the trend of COVID-19 and its relationship with some meteorological parameters from March 1 to May 31, 2020. For the climatic data, the monthly minimum, maximum and mean temperature and minimum, maximum and mean relative humidity are the averaged based on daily parameters obtained from March to May. The daily average minimum, maximum and mean were calculated by averaging the daily minimum and maximum temperatures. The same method is applied for the relative humidity to obtain the daily average. MATLAB and the statistical package of $\mathrm{R}$ software were used to perform all computational tasks in this work.

First of all, we analyzed the situation pandemic in West Africa by cumulating the confirmed cases of COVID-19 in the sub-region. This analysis allows us to see the COVID-19 evolution in West Africa between March 1 and May 31, 2020. Indeed, it allows likewise to identify countries which recorded lower and highest confirmed cases of COVID-19 in West Africa.

Secondly, we focus on our study area which is Conakry to do the same method on COVID-19 and death cases. This analysis allows to identify the days 
where lower and highest confirmed cases of COVID-19 and deaths are recorded in Conakry, Guinea.

Third, we analyze the relationship between meteorological factors (temperature and relative humidity) and the daily confirmed cases counts of COVID-19 from the correlation of Pearson. The correlation coefficients allow us to determine the links between both parameters. We normalize all parameters and COVID-19 data to analyze their relation. In addition, we calculated the correlation between:

- COVID-19 and minimum temperature ( $\mathrm{T}_{\min }$, hereafter),

- COVID-19 relative humidity minimum ( $\mathrm{RH}_{\min }$, hereafter),

- COVID-19 and maximum temperature ( $\mathrm{T}_{\max }$, hereafter),

- COVID-19 and relative humidity maximum ( $\mathrm{RH}_{\max }$, hereafter),

- COVID-19 and mean temperature ( $\mathrm{T}_{\text {mean }}$, hereafter),

- COVID-19 and relative humidity mean ( $\mathrm{RH}_{\text {mean }}$, hereafter).

Fourth, we analyze also the relationship between COVID-19 and meteorological factors by the multi-linear regression model. In statistics, multiple linear regression is a mathematical regression method extending simple linear regression to describe the variations of an endogenous variable associated with the variations of several exogenous variables.

The multi-linear regression model is also used to describe relationships between variables by fitting a line to the observed data. The regression allows estimating how a dependent variable changes as the independent variable(s) change. This technique is applied to estimate the relationship between two or more independent variables such as temperature $\left(\mathrm{T}_{\min }, \mathrm{T}_{\max }\right.$ and $\left.\mathrm{T}_{\text {mean }}\right)$, relative humidity $\left(\mathrm{RH}_{\min }, \mathrm{RH}_{\max }\right.$ and $\mathrm{RH}_{\text {mean }}$ ), and one dependent variable which is the observed COVID-19 cases.

To be able to provide multi-linear regression analysis, R-package's programming language was employed to conduct a numerical code. The relationship between climate variables and COVID-19 spread is then assessed for the Lmrob is non-parametric simple linear regression method based on MM-estimator for linear regression models. The procedure proposed in the algorithm has been implemented in the R-package "robust-base" and provides different robust regression techniques, as well as robust univariate and multivariate methods.

\subsection{Statistical Analysis}

Several calculated techniques of correlation exist such as Pearson, Spearman or Kendall were adopted to explore the relationship between two variables. For this study we used Pearson method. Pearson correlation measures the existence (given by a $\mathrm{p}$-value) and strength (given by the coefficient $\mathrm{r}$ between -1 and +1 ) of a linear relationship between two variables [30].

The relationship (or the correlation) between the two variables is denoted by the letter $r$ and quantified with a number, which varies between -1 and +1 [31]. Pearson method considers the relationship between two sets of variables $\mathrm{X}$ (in- 
dependent) and Y (dependent). This method was applied to statistically determinate the relationship between COVID-19 and meteorological factors. According to [32] an absolute value of $\mathrm{r}$ of 0.1 is classified as small, an absolute value of 0.3 is classified as medium and of 0.5 is classified as large. The Pearson Correlation Coefficient $r$ is given as:

$$
r(x, y)=\frac{1}{N} \sum_{i=1}^{N} \cdot \frac{\left(x_{i}-\bar{x}\right)\left(y_{i}-\bar{y}\right)}{\sigma_{x} \cdot \sigma_{y}}
$$

where:

- $r$ is Pearson correlation coefficient between $x$ and $y$,

- $N$ is the number of pairs of the measurement;

- $\bar{X}$ equals to Mean of $x$ variable;

- $\bar{y}$ equals to Mean of $y$ variable;

- $\sigma_{x}$ and $\sigma_{y}$ are standard Deviation of $x$ and $y$ calculated as;

- $\sigma_{x}$ equals to $\left(x_{i}-\bar{x}\right)^{2}$ and $\sigma_{y}$ equals to $\left(y_{i}-\bar{y}\right)^{2}$.

\section{Results}

In this section the COVID-19 trend from March 1 to May 31, 2020 in the West African region which comprises the Republic of Guinea is depicted.

\subsection{Evolution of COVID-19 in West Africa}

Figure 5 shows a sharp increase in the accumulated, cases of COVID-19 in West Africa countries from March 1 to May 31, 2020. This quick increase is mainly noted for Ivory Coast, Senegal, Guinea, Ghana and Nigeria varying from 1500

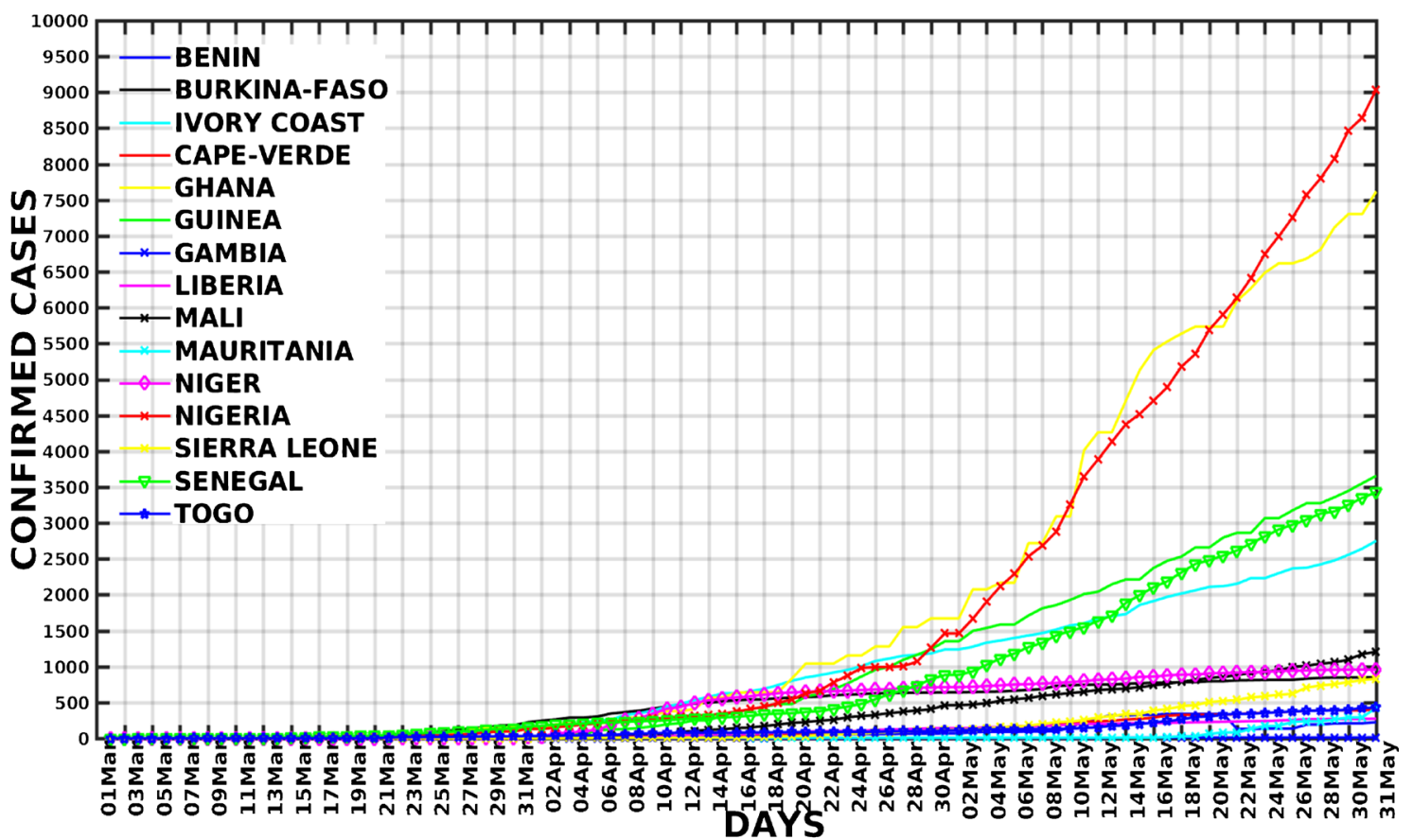

Figure 5. Cumulative numbers of confirmed cases of COVID-19 in West Africa between March 1 to May 31, 2020. The $\mathrm{x}$-axis and $\mathrm{y}$-axis are respectively days and confirmed cases. 
to 10,000 confirmed cases on May 31. In Sierra Leone, Burkina-Faso, Niger and Mali, low confirmed cases recorded rating from 500 to 1500 cases on May 31. However, the lowest increases of confirmed cases were identified in Gambia, Mauritania, Togo, Benin, Cape-Verde and Liberia in both the daily new cases and total confirmed cases during the studied period. Nigeria has the highest confirmed cases (9587), followed by Ghana (7768), Guinea (3706), Senegal (3535), Ivory Coast (2799). Mali, Niger, Burkina-Faso and Sierra Leone recorded respectively 1230, 956, 853 and 852 confirmed cases of COVID-19 and Gambia has the lowest cases number of confirmed cases (11). The number of recorded cases in Guinea during the study period was estimated to 3706 confirmed cases.

During the first week of March 2020, 4 confirmed cases were recorded in Senegal and 1 confirmed case in Togo was observed. During the second week, starting from March 14, 2020 a total of 132, 79 and 69 confirmed cases until the end of the third week were recorded respectively in Ghana, Senegal and Burkina Faso. During the last week of March, the confirmed cases number have exceeded 140 in Burkina Faso (216 cases), Ivory Coast (168 cases), Senegal (159 cases), Cameroun (142 cases) and Nigeria (140 cases). Therefore, during the month of March, the highest confirmed cases in the western Africa were recorded by descending order in Burkina-Faso, Ivory Coast, Senegal, Cameroun and Nigeria.

During the first week of April 2020, an upward trend was observed in the confirmed cases in Niger (233 cases), Ivory Coast (155 cases), Burkina-Faso (142 cases), Guinea (112 cases), Nigeria (107 cases), Senegal (64 cases) and Sierra Leone (11 cases). Therefore, Senegal and Sierra Leone have relatively the lowest increment in the number of recorded confirmed cases. From the second week to the last week of April, the trend remains in the number of confirmed cases strongly increased in most of the west African countries in general like Nigeria (1330 cases), Ivory Coast (1070 cases), Senegal (720 cases), Niger (693 cases), Burkina-Faso (419 cases) and particularly in Guinea (1335 cases).

During the first week of May 2020, we have observed that the trend of confirmed cases was still increasing with reaching a pic of 2500 cases, in Nigeria and Ghana, Guinea (1750 cases), Ivory Coast (1500 cases), and Senegal (1400 cases). This positive trend in numbers of recorded confirmed cases persisted in these countries until the end of May. Nevertheless, the slope of the trend was different from one country to another, resulting in the level of which the given country is affected by the COVID-19.

\subsection{Evolution of COVID-19 in Conakry}

\subsubsection{Total COVID-19 Infected Confirmed and Death Cases}

Figure 6 shows the evolution curve of COVID-19 recorded confirmed cases (Figure 6(a)) and the number of recorded deaths due to COVID-19 (Figure 6(b)) from March 1 to May 31, 2020 in Conakry, Guinea. Figure 6(a) shows an increasing trend of COVID-19. The first case of COVID-19 was recorded by the NAHS of Guinea 19 on March 12, 2020. This means that in the first 11 days of the March month, Guinea had zero confirmed cases up to March 12, 2020. The 

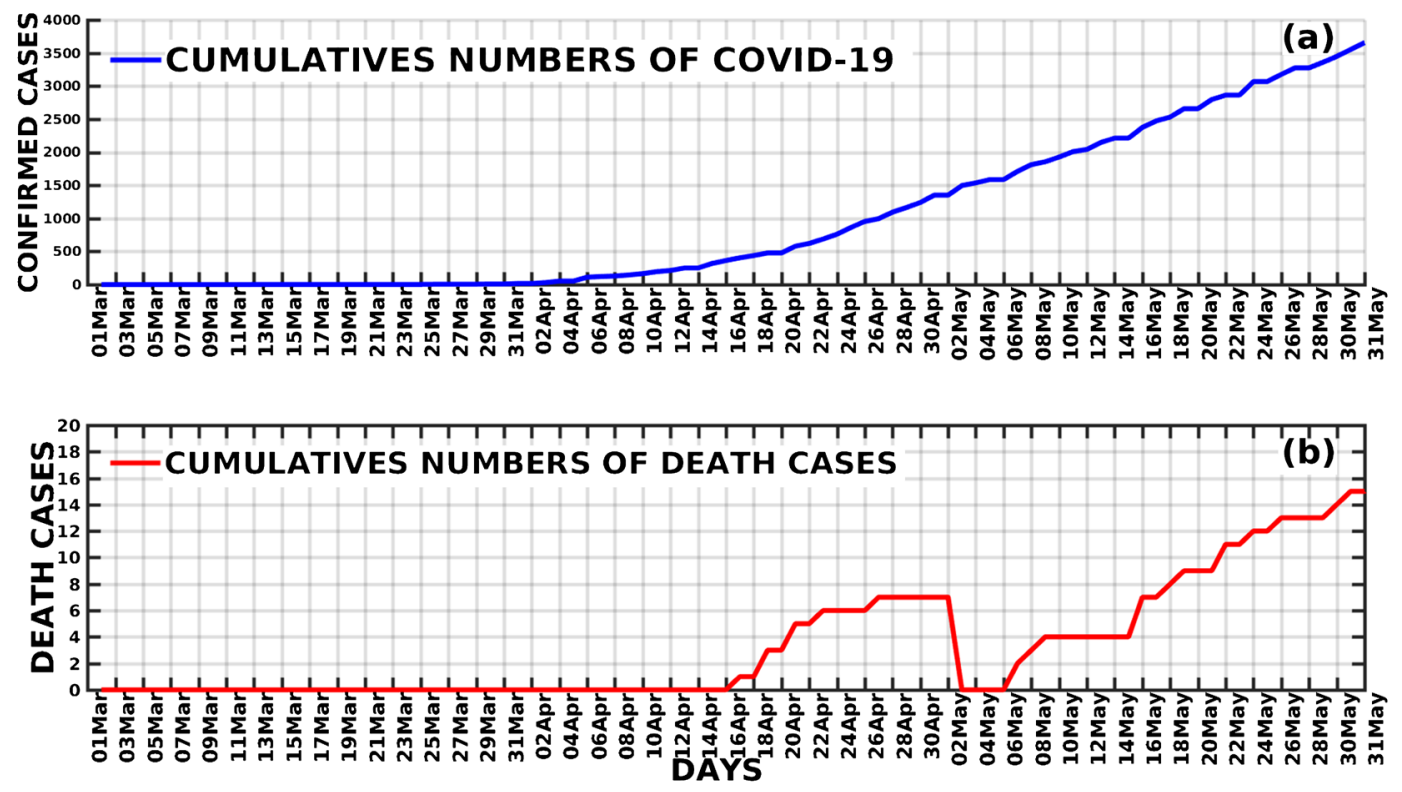

Figure 6. Cumulative numbers of confirmed cases: (a) and (b) corresponds respectively COVID-19 and Death cases curves evolution in Conakry (Republic of Guinea) between March 1 and May 31, 2020.

second confirmed cases were recorded on March 20 and the number kept increasing to reach a total of 16 confirmed cases by the end of March 2020.

During the first week of April 2020, the number of cases increased from 16 to 100 confirmed cases. The same trend continues during the second week to reach a pic of 1351 cases. The month of May is characterized by an unprecedented and alarming increase in the number of COVID-19 confirmed cases. The confirmed cases drastically increased from 1351 to 1750, during the first week of May 2020. This trend continues to reach the pic of 3706 confirmed cases, which positioned Guinea among the most affected west African countries.

Figure 6(b) presents evolution curve of death cases recorded in Conakry due to COVID-19 between March and May 2020. As per see Figure 6(b), the whole of March, despite the slight increase in the number of confirmed cases recorded no deaths due to COVID-19. The first death of COVID-19 in Conakry was recorded on April 16, 2020, and the highest case is 15 recorded on May 31, 2020. The last two weeks of April and May between 16 and the end of month respectively are marked by a trend increasing of death cases. The highest number of death cases per day was 7, recorded from April 26 to April 30.

The month of May was identified having the highest morbidity and mortality due to COVID-19, with a minimum of 2 recorded cases per day throughout the month, except on May 2 and May 4.

\subsection{Relationship between COVID-19 and Meteorological Factors (Temperature, Relative Humidity)}

Meteorological factors as relative humidity and temperature have been reported to play a significant role in the seasonal spread of coronaviruses as indicated [33] [34], in China. This section shows the relationship of meteorological factors with 
COVID-19 in Guinea between March 1 and April 30, 2020.

\subsubsection{COVID-19 and Meteorological Factors ( $\mathrm{T}_{\text {mean }}$ and $\mathrm{RH}_{\text {mean }}$ )}

Figure 7 shows the anomalies of daily confirmed cases of COVID-19 and mean temperature (black curve) in the study period in Conakry, Republic of Guinea. This figure shows the evolution of COVID-19 and $\mathrm{T}_{\text {mean }}$ curve with different behavior. We noticed that the trend of COVID-19 curve is increasing while that of temperature is decreasing. Our findings are confirmed by a very weak negative correlation coefficient value $(r=-0.29$, $\mathrm{p}$-value $=0.00468)$, which means that these two parameters are anti-correlated.

Figure 7 shows likewise, the relationship between confirmed cases of COVID-19 and mean relative humidity in Conakry. We observed that the two parameters evolve together in the same direction with an increasing trend. This relationship is depicted by the weak but positive Pearson correlation coefficient $(r=0.36)$, which implies that as the $\mathrm{RH}_{\text {mean }}$ highest, the number of cases increases. Likewise, if the $\mathrm{RH}_{\text {mean }}$ lowers, the number of confirmed cases decreases.

\subsubsection{COVID-19 and Meteorological Factors ( $\mathrm{T}_{\min }$ and $\mathrm{RH}_{\min }$ )}

Figure 8 shows the anomalies of daily confirmed cases of COVID-19 pandemic and meteorological factors $\left(\mathrm{T}_{\min }, \mathrm{RH}_{\min }\right)$ in the study in Conakry. In this figure, the behavior of COVID-19 (curve red) is decreasing, while that for $\mathrm{T}_{\min }$ (black curve) evolves differently. We noticed also an opposition of behavior from $19^{\text {th }}$ to $27^{\text {th }}$ day and the correlation ( $\mathrm{r}$ ) coefficient value between COVID-19 and $\mathrm{T}_{\min }$ is $r=-0.12$ which is relatively low. These results indicate that the relationship between the confirmed cases of COVID-19 and $\mathrm{T}_{\min }$ is anti-correlated. In other words, confirmed cases of COVID-19 are opposed proportionally to the minimum temperature.

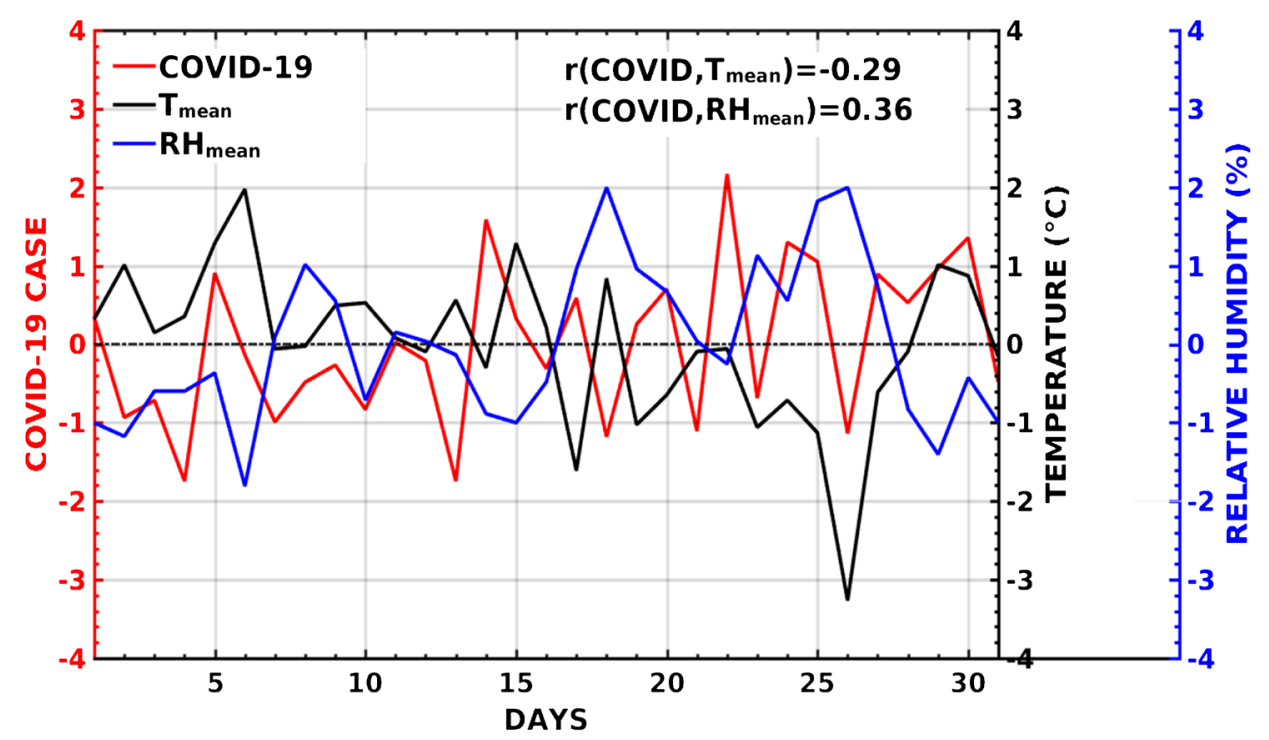

Figure 7. Anomalies of COVID-19, mean relative humidity $\left(\mathrm{RH}_{\text {mean }}\right)$ and mean temperature $\left(\mathrm{T}_{\text {mean }}\right)$ in Conakry. The red, black and blue curve are respectively COVID-19 cases, $\mathrm{T}_{\text {mean }}$ and $\mathrm{RH}_{\text {mean }}$ from March 1 to May 31, 2020. 


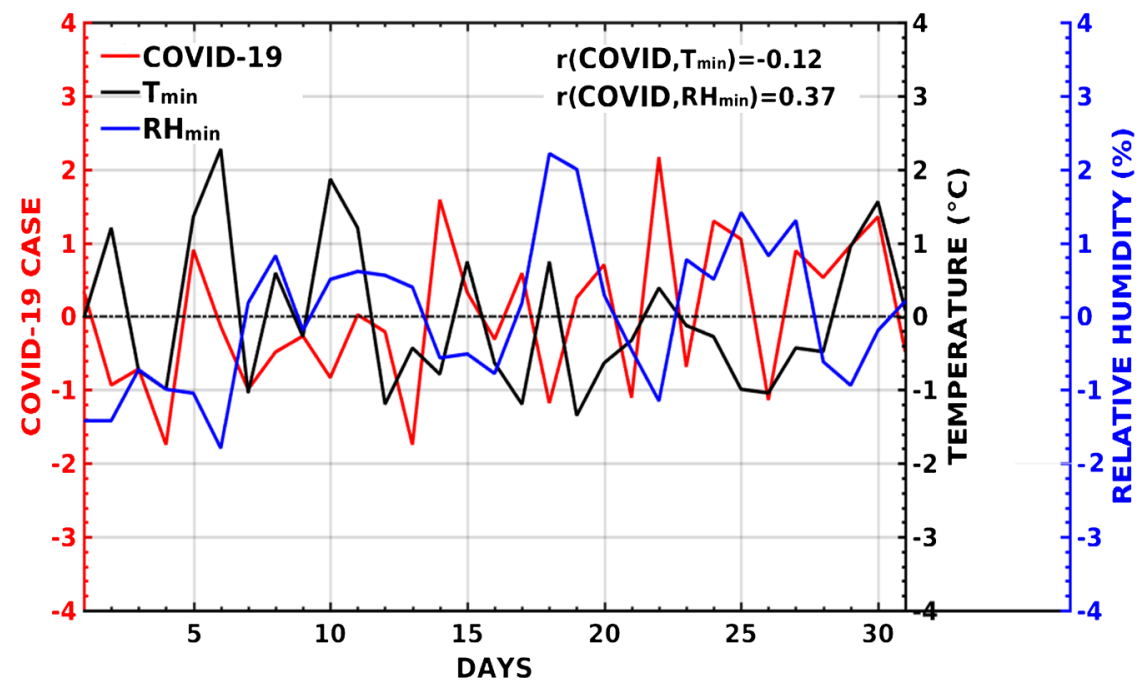

Figure 8. Anomalies of COVID-19, minimum relative humidity $\left(\mathrm{RH}_{\min }\right)$ and minimum temperature $\left(\mathrm{T}_{\mathrm{min}}\right)$ in Conakry. The red, black and blue curve are respectively COVID-19 cases, $\mathrm{T}_{\min }$ and $\mathrm{RH}_{\min }$ from March 1 to May 31, 2020.

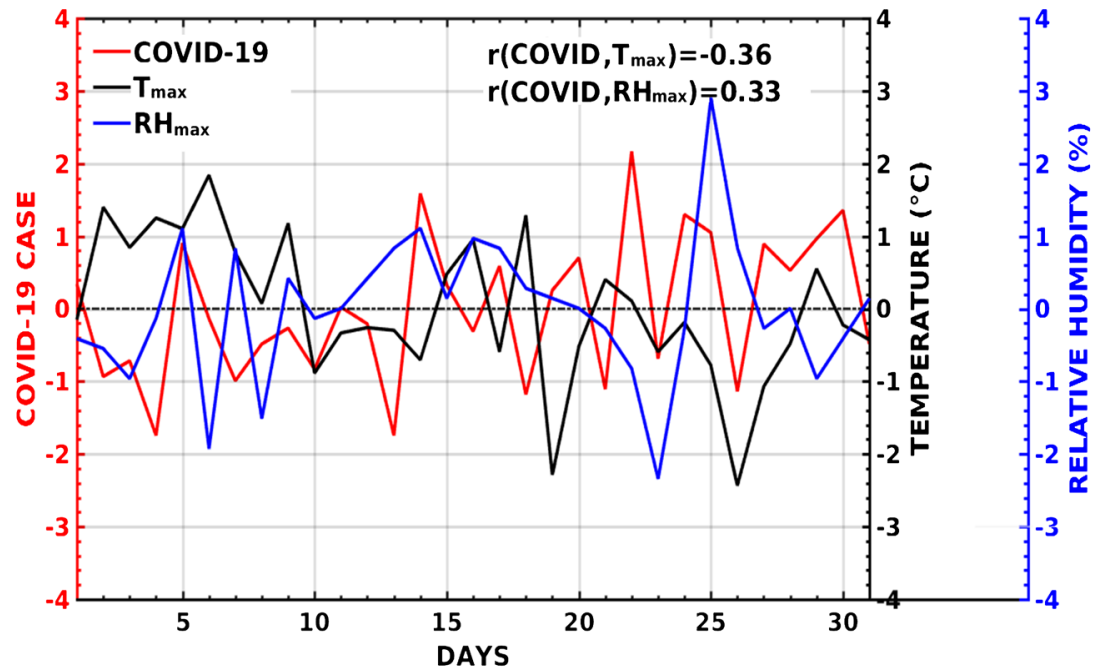

Figure 9. Anomalies of COVID-19, minimum Relative Humidity $\left(\mathrm{RH}_{\max }\right)$ and minimum temperature $\left(\mathrm{T}_{\max }\right)$ in Conakry. The red, black and blue curve are respectively COVID-19 cases, $\mathrm{T}_{\max }$ and $\mathrm{RH}_{\max }$ from March 1 to May 31, 2020.

Figure 8, shows that both COVID-19 number of cases and relative humidity evolves in the same direction with significant pearson correlation coefficient $(\mathrm{r}=$ $0.37^{\star *}$ ) at $95 \%$ confidence level. On the contrary, a negative correlation was observed between the COVID-19 number of cases and the temperature $(r=-0.12)$.

\subsubsection{COVID-19 and Meteorological Factors ( $\mathrm{T}_{\max }$ and $\mathrm{RH}_{\max }$ )}

Figure 9 exhibits the anomalies of daily confirmed cases of COVID-19 and meteorological factors $\left(\mathrm{T}_{\max }, \mathrm{RH}_{\max }\right)$ in Conakry. We noticed that the trend of COVID-19 curve is increasing while that of $\mathrm{T}_{\max }$ is decreasing. This result is confirmed by the negative correlation ( $r$ ) coefficient value equal to -0.36 , which means that these two parameters are anti-correlated. 
Between COVID-19 and $\mathrm{RH}_{\max }$, we observed in Figure 9 that they evolve together in the same direction with except for the last week of the month. The correlation coefficient value is somewhat positive $(r=0.33)$ and relatively low, this means that they are correlated.

\subsubsection{Correlation Matrix between COVID-19 and Meteorological Factors}

Figure 10 summarizes the relationship between confirmed cases of COVID-19 and meteorological factors in Conakry. It shows an anti-correlation between COVID-19 and $\mathrm{T}_{\text {mean }}\left(\mathrm{r}=-0.29^{\star *}\right), \mathrm{T}_{\min }\left(\mathrm{r}=-0.12^{\star}\right), \mathrm{T}_{\max }\left(\mathrm{r}=-0.36^{\star *}\right)$. But between COVID-19 and $\mathrm{RH}_{\text {mean }}\left(\mathrm{r}=0.36^{\star *}\right), \mathrm{T}_{\min }\left(\mathrm{r}=0.37^{\star *}\right)$ and $\mathrm{T}_{\max }\left(\mathrm{r}=0.33^{\star *}\right)$, Figure 10 indicates a positive correlation.

We observed that those Pearson coefficients of correlation are significant with p-values $<0.01$. We noted that among these Pearson correlation coefficients: $\mathrm{T}_{\text {mean }}, \mathrm{T}_{\max }$ and $\mathrm{RH}_{\text {mean }}, \mathrm{RH}_{\text {min }}, \mathrm{RH}_{\text {max }}$ are respectively anti-correlated and correlated with $\mathrm{p}$-value $<0.01$. But, except the $\mathrm{T}_{\min }$ which is not significantly $\left(^{*}\right)$ anti-correlated with COVID-19.

\subsubsection{Analysis of the Relationship between COVID-19 and Climate Va- riables Using a Multi-Regression Model}

Figure 11 shows statistically significant relationship between confirmed COVID-19 and multiple climate variables such as the temperature, humidity $\left(\mathrm{T}_{\text {mean }}, \mathrm{T}_{\min }\right.$, $\mathrm{T}_{\max }, \mathrm{RH}_{\text {mean }}, \mathrm{RH}_{\min }$ and $\mathrm{RH}_{\max }$ ). Linear trends are estimated using a robust and non-parametric regression model and corresponding Pearson correlation coefficients values ( $r$ ) are added for each climate variable contributions. These results imply that in Guinea, the COVID-19 transmission is somewhat influenced by a

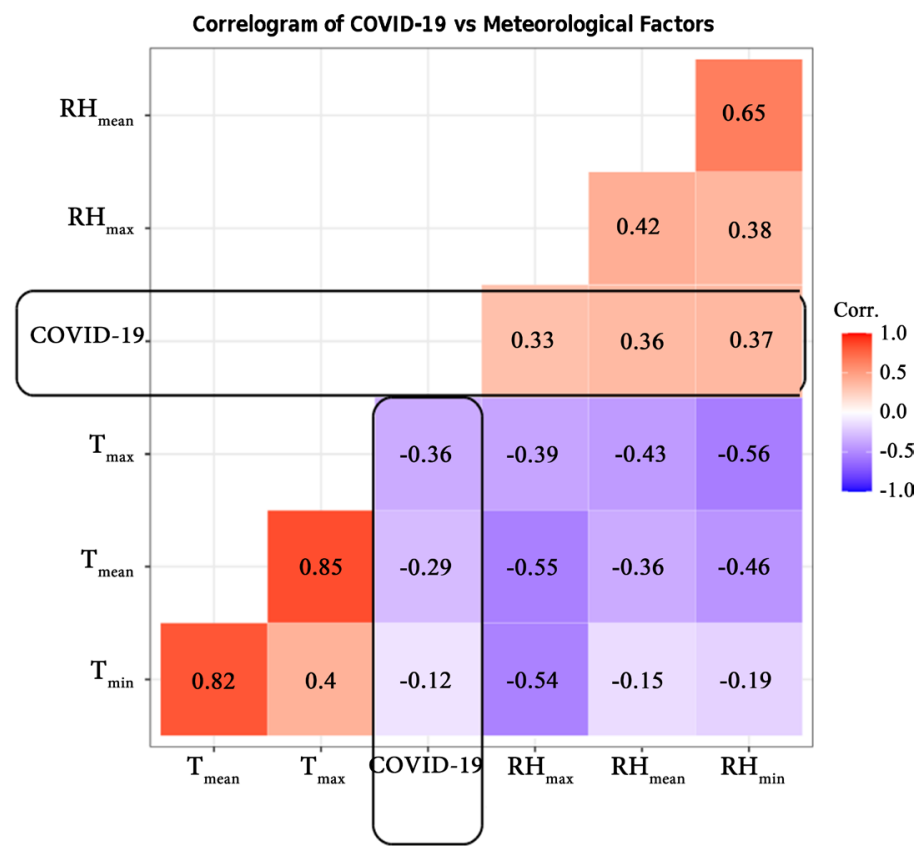

Figure 10. Correlation matrix depicting the strength of the association between COVID-19 number of cases and meteorological factors. We consider the area framed in black. 


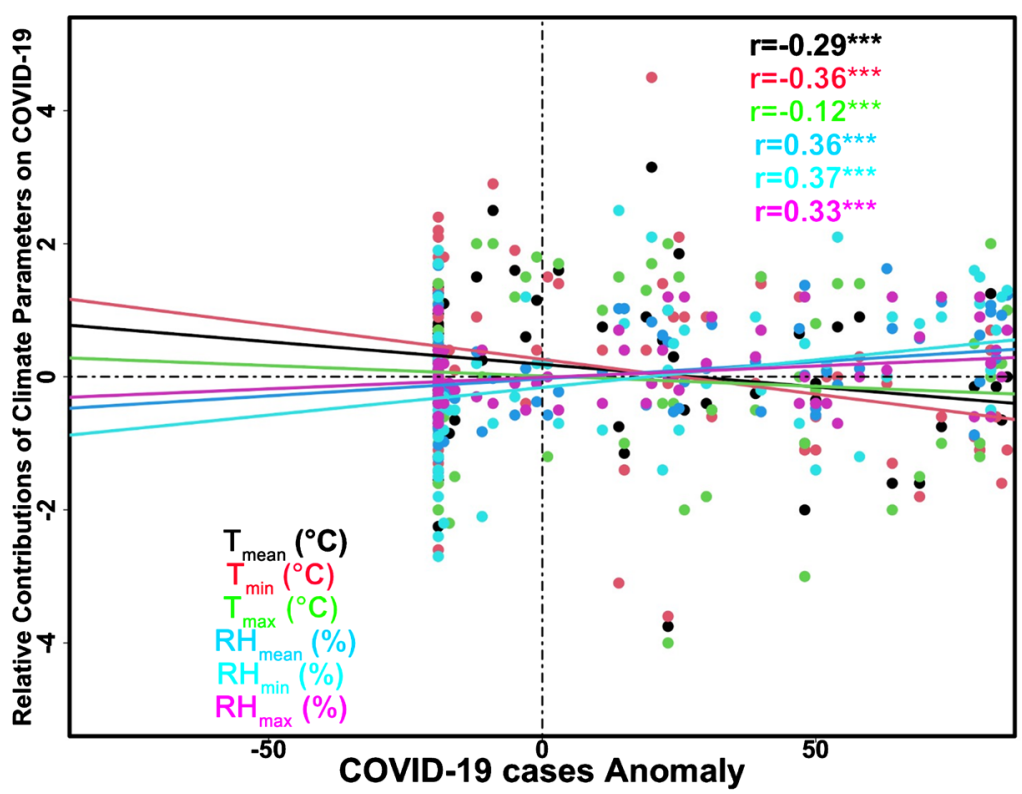

Figure 11. Contribution of climate parameters to COVID-19 transmission between March 1 and May 31, 2020, Conakry. For each climate variable, the relationship between the number of COVID-19 cases (x-axis) versus temperature $\mathrm{T}_{\text {mean }}, \mathrm{T}_{\min }, \mathrm{T}_{\max }, \mathrm{RH}_{\text {mean }}$, $\mathrm{RH}_{\min }$ and $\mathrm{RH}_{\max }$. A star symbols are added when the correlation is significant: ${ }^{\star *}$ for $\mathrm{p}$-value $<0.01,{ }^{* *}$ for $\mathrm{p}$-value $<0.05$ and ${ }^{*}$ for $\mathrm{p}$-value $<0.1$.

decrease of temperature associated with an increase of humidity.

\section{Discussions}

This study is the first of its kind that has been undertaken in Guinea in general and in Conakry particularly. Our results indicated that COVID-19 transmission may be affected by meteorological factors like temperature (minimum, maximum and mean) and relative humidity (minimum, maximum and mean). A weak negative correlation was obtained between COVID-19 and $\mathrm{T}_{\text {mean }}, \mathrm{T}_{\min }, \mathrm{T}_{\max }$ in one hand and a positive correlation on the other hand between COVID-19 and $\mathrm{RH}_{\text {mean }}, \mathrm{RH}_{\min }, \mathrm{RH}_{\max }$.

The negative correlation value between COVID-19 and $\mathrm{T}_{\text {mean }}$ implies that as the temperature lower, the number of cases increases. This result is consistent with previous studies done by [35] [36] [37] [38]. It is observed that when $T_{\text {mean }}$ increases, the number of COVID-19 cases decreases drastically. The same observation was made previously by [39] and [38] over on Turkey. Pirouz et al. (2020) also have the same conclusion from the correlation of $\mathrm{T}_{\text {mean }}$ with the COVID-19 cases in Iran and Italy. The findings of [40] on climate indicators have shown that temperature serves as a driver for the COVID-19, for our study case it is $\mathrm{T}_{\text {mean }}$.

The positive correlation value obtained between COVID-19 and $\mathrm{RH}_{\text {mean }}$ means that they evolve together, therefore are likewise proportional. Auler et al. (2020) [41] also came to the same conclusion over the Brazilian cities, indicating a positive correlation between humidity and the COVID-19 transmission. This deduc- 
tion is consistent with [42] that explained the spread of COVID-19 in provinces by the high population density, intra-provincial movements of population but most importantly by the high humidity.

From the results, the relationship between $\mathrm{T}_{\min }$ and COVID-19 showed a negative correlation coefficient. Therefore, when $\mathrm{T}_{\min }$ increase this correspond to a decreasing of COVID-19 in Conakry. It agrees with [40] who shown on Iran and Italy that, the regions with lower average daily temperature had a higher epidemic level of the new coronavirus (COVID-19) like [43] in New York City. It can allow us to deduce that a minimum temperature correlated with COVID-19 be could be a factor in the spread of COVID-19 in Conakry, Guinea. This deduction is coherent with [43] and [44] have concluded that the countries currently suffering most from the disease (COVID-19) are mostly located in the regions with low temperatures. Then, [25] [44] [45] [46] [47] [48] are unanimous on the fact that weather with low temperature favors its transmission.

The relationship between COVID-19 and $\mathrm{T}_{\max }$ exhibits a behanvior opposed. That is means that the trend of COVID-19 is increasing while that of $\mathrm{T}_{\max }$ is decreasing, therefore they are anti-correlated. This is agreed with [39] and [38]. Poole, (2020) [39] explains that the high $\mathrm{T}_{\text {mean }}\left(\mathrm{T}_{\max }\right)$ seems to lead to the reduction of the number of COVID-19 cases. Şahin et al. (2020) [38] indicates that a maximum temperature correlated with COVID-19 would be useful in suppressing COVID-19.

Considering COVID-19 and $\mathrm{RH}_{\max }$, we obtained a positive correlation coefficient. This idea agrees with the works of [42] on Iran, who have indicated that the province's towns are more susceptible to COVID-19's infection because of the high humidity rate. Ma et al. (2020) [1] suggested that humidity would play an important role in mortality rate from COVID-19, which means clearly that high RH could be a factor in the spread of the COVID-19 in Conakry city.

The findings on the multi-regression model are consistent with some investigations available in the literature [49], showing that temperature can hold no significant associations with a cumulative incidence rate of COVID-19 and the spreadability of COVID-19 would not change with increasing temperature.

To summarize, Liu, J et al., 2018 [25], Liu, J et al., 2020 [44], Tan et al., 2020 [45], Lin K et al., 2006 [46] and Park et al., 2020 [47] are unanimous on the fact that a weather with low temperature, mild diurnal temperature range and high humidity likely favor its transmission. Also, Lin J et al., 2020 [50] found that the high humidity promotes COVID-19 transmission when the temperature is low but reduces COVID-19 transmission when the temperature is high.

\section{Conclusions}

The aim of this study was to examine the relationship between coronavirus disease 2019 (COVID-19) cases and some meteorological factors such as temperature and relative humidity in Conakry, from March 1 to May 31, 2020 in order to understand the extent to which they can contribute to the spread of the 
COVID-19 in the given geographic location.

Our analysis on West African countries exhibits a sharp increase of confirmed cases from March 1 to May 31, 2020 in eight countries including Guinea, with the highest confirmed cases recorded in Nigeria followed by Ghana and Guinea. From the total number of confirmed cases, Guinea was one of the most affected countries in the western part of Africa between March and May 2020. The month of May was observed as the month with the highest morbidity and mortality rate, recording a minimum of 2 deaths per day.

This study found that the $T_{\text {mean }}, T_{\min }$ and $T_{\max }$ are anti-correlated with COVID-19 confirmed cases in Conakry. The negative values of correlation associated between COVID-19 and relative humidity show that when they are correlated this could be a factor in the spread of the coronavirus until death follows in Conakry. It also shows that the $\mathrm{RH}_{\text {mean }}, \mathrm{RH}_{\min }$ and $\mathrm{RH}_{\max }$ are correlated with COVID-19 indicating a positive correlation. Therefore, the high temperature and high low relative humidity could be a factor in the reduced spread of the COVID-19 cases in Conakry. It is assumed henceforth, from the correlation analysis, that the increase in $\mathrm{RH}_{\text {mean }}$ and $\mathrm{T}_{\text {mean }}$ could be the meteorological factors among others explaining the climatic conditions favourable to the spread of COVID-19 in Conakry city.

This study indicates that the epidemic might gradually increase as a result of low temperatures summer in the coming months flowing the high humidity. But the implementation of public health control measures and barrier gestures could slow its spread. In our study, despite some coherences with others study between meteorological factors and COVID-19, some limits are known. In the future more variables will be needed to conduct a comprehensive study on the COVID-19. A study considering other COVID-19 related factors such as social distancing, people's immunity, availability of health facility etc. might be of paramount importance.

The present study can be considered as a springboard for further researches that strive to understand the relationship between meteorological parameters and COVID-19 in Guinea and elsewhere. The study would have substantial implications for directing COVID-19 surveillance activities, with a special attention to the onset of the rainy season, a period in which the lowest temperature and highest humidity are recorded in the country. The study recommends the intensification of mass sensitization during this period. The study also recommends that habitations and hospital rooms should be kept in relatively low humidity and relatively higher temperature to minimize the spread of the (SARS-CoV-2).

In addition, epidemiologic modelling framework including climate could lead to the development of an early warning system for COVID-19 in Guinea and elsewhere.

\section{Acknowledgements}

Authors express their gratitudes to the following institutions and individuals: 1) 
National Meteorology Service of Guinea (NMSG) for helping to get meteorological data; 2) To the Laboratoire de Physique de l'Atmosphère et de l'Océan Siméon-Fongang (LPAO-SF) of the Université Cheikh Anta Diop of Dakar for the warm welcome and the creation of ideal working conditions; 3) To the Laboratoire d'Enseignement et de Recherche en Energétique Appliquée (LEREA) of the University Gamal Abdel Nasser of Conakry for the establishment of a successful collaboration between the two institutes; 4) Copperbelt University, School of Natural Resource, Department: Plant and Environmental science, Zambia; 5) NOAA Center for Weather and Climate Prediction, 5830 University Research Court, College Park, Maryland, USA; 6) To all the supervisors and colleagues of the different Laboratories for the good spirit of collaboration that characterized the conduct of the research activities; 7) Special thanks to the anonymous reviewers for their constructive comments.

\section{Conflicts of Interest}

The authors declare no conflicts of interest regarding the publication of this paper.

\section{References}

[1] Ma, Y., Zhao, Y., Liu, J., He, X., Wang, B., Fu, S., et al. (2020) Effects of Temperature Variation and Humidity on the Death of COVID-19 in Wuhan, China. Science of the Total Environment, 724, Article ID: 138226. https://doi.org/10.1016/j.scitotenv.2020.138226

[2] Gorbalenya, A. E., Baker, S. C., Baric, R., Groot, R. J. D., Drosten, C., Gulyaeva, A. A., et al. (2020) Severe Acute Respiratory Syndrome-Related Coronavirus: The Species and Its Viruses-A Statement of the Coronavirus Study Group. bioRxiv. https://doi.org/10.1101/2020.02.07.937862

[3] Wu, F., Zhao, S., Yu, B., Chen, Y.M., Wang, W., Song, Z.G., et al. (2020) A New Coronavirus Associated with Human Respiratory Disease in China. Nature, 579, 265-269. https://www.nature.com/articles/s41586-020-2008-3 https://doi.org/10.1038/s41586-020-2008-3

[4] Zhou, F., Yu, T., Du, R., Fan, G., Liu, Y., Liu, Z., et al. (2020) Clinical Course and Risk Factors for Mortality of Adult Inpatients with COVID-19 in Wuhan, China: A Retrospective Cohort Study. The Lancet, 395, 1054-1062. https://doi.org/10.1016/S0140-6736(20)30566-3

[5] Jiang, F., Deng, L., Zhang, L., Cai, Y., Cheung, C.W. and Xia, Z. (2020) Review of the Clinical Characteristics of Coronavirus Disease 2019 (COVID-19). Journal of General Internal Medicine, 35, 1545-1549. https://doi.org/10.1007/s11606-020-05762-w

[6] Rodriguez-Morales, A.J., Bonilla-Aldana, D.K., Tiwari, R., Sah, R., Rabaan, A.A. and Dhama, K. (2020) COVID-19, an Emerging Coronavirus Infection: Current Scenario and Recent Developments-An Overview. Journal of Pure and Applied Microbiology, 14, Article No. 6150. https://doi.org/10.22207/JPAM.14.1.02 https://www.researchgate.net/profile/Alfonso_Rodriguez-Morales/publication/3398 $\underline{48627}$

[7] Boukhatem, M.N. (2020) Novel Coronavirus Disease 2019 (COVID-19) Outbreak 
in Algeria: A New Challenge for Prevention. Journal of Community Medicine and Health Research, 5, Article No. 1035.

[8] Wang, C., Horby, P.W., Hayden, F.G. and Gao, G.F. (2020) A Novel Coronavirus Outbreak of Global Health Concern. The Lancet, 395, 470-473.

https://doi.org/10.1016/S0140-6736(20)30185-9

[9] Wang, M., Jiang, A., Gong, L., Luo, L., Guo, W., Li, C., et al. (2020) Temperature Significant Change COVID-19 Transmission in 429 Cities. MedRxiv. https://doi.org/10.1101/2020.02.22.20025791

[10] Covid, C.D.C. and Team, R. (2020) Severe Outcomes among Patients with Coronavirus Disease 2019 (COVID-19) -United States, February 12-March 16, 2020. Morbidity and Mortality Weekly Report, 69, 343-346.

https://doi.org/10.15585/mmwr.mm6912e2

[11] World Health Organization (2020) WHO Characterizes COVID-19 as a Pandemic. World Health Organization, Geneva.

https://www.who.int/emergencies/diseases/novel-coronavirus-2019/events-as-theyhappen

[12] World Health Organization (2020) Coronavirus Disease 2019 (COVID-19) Situation Report, No. 68. World Health Organization, Geneva.

https://www.who.int/docs/default-source/coronaviruse/situation-reports/20200328sitrep-68-COVID-19.pdf?sfvrsn $=384 \mathrm{bc} 74 \mathrm{c} 2$

[13] European Centre for Disease Prevention and Control (2020) Download Historical Data (to 14 December 2020) on the Daily Number of New Reported COVID-19 Cases and Deaths Worldwide.

https://www.ecdc.europa.eu/en/publications-data/download-todays-data-geographi c-distribution-COVID-19-cases-worldwide

[14] Brett Finlay, B., See, R.H. and Brunham, R.C. (2004) Rapid Response Research to Emerging Infectious Diseases: Lessons from SARS. Nature Reviews Microbiology, 2, 602-607. https://www.nature.com/articles/nrmicro930\#appendices https://doi.org/10.1038/nrmicro930

[15] Ji, W., Wang, W., Zhao, X., Zai, J. and Li, X. (2020) Cross-Species Transmission of the Newly Identified Coronavirus 2019-nCoV. Journal of Medical Virology, 92, 433-440. https://doi.org/10.1002/jmv.25682

[16] Li, X., Song, Y., Wong, G. and Cui, J. (2020) Bat Origin of a New Human Coronavirus: There and Back again. Science China Life Sciences, 63, 461-462. https://doi.org/10.1007/s11427-020-1645-7

[17] Thienemann, F., Pinto, F., Grobbee, D.E., Boehm, M., Bazargani, N., Ge, J. and Sliwa, K. (2020) World Heart Federation Briefing on Prevention: Coronavirus Disease 2019 (COVID-19) in Low-Income Countries. Global Heart, 15, 31.

https://doi.org/10.5334/gh.778

[18] Amodio, E., Vitale, F., Cimino, L., Casuccio, A. and Tramuto, F. (2020) Outbreak of Novel Coronavirus (SARS-CoV-2): First Evidences from International Scientific Literature and Pending Questions. Healthcare, 8, Article No. 51.

https://doi.org/10.3390/healthcare8010051

[19] Wang, J., Tang, K., Feng, K. and Lv, W. (2020) High Temperature and High Humidity Reduce the Transmission of COVID-19. arXiv: 2003.05003.

[20] Kudo, E., Song, E., Yockey, L.J., Rakib, T., Wong, P.W., Homer, R.J. and Iwasaki, A. (2019) Low Ambient Humidity Impairs Barrier Function and Innate Resistance against Influenza Infection. Proceedings of the National Academy of Sciences of the United States of America, 116, 10905-10910. 
https://doi.org/10.1073/pnas.1902840116

[21] Price, R.H.M., Graham, C. and Ramalingam, S. (2019) Association between Viral Seasonality and Meteorological Factors. Scientific Reports, 9, Article No. 929. https://doi.org/10.1038/s41598-018-37481-y

[22] Lowen, A.C. and Steel, J. (2014) Roles of Humidity and Temperature in Shaping Influenza Seasonality. Journal of Virology, 88, 7692-7695. https://doi.org/10.1128/JVI.03544-13

[23] Memarzadeh, B. and Mosallaei, H. (2011) Array of Planar Plasmonic Scatterers Functioning as Light Concentrator. Optics Letters, 36, 2569-2571. https://doi.org/10.1364/OL.36.002569

[24] Tan, J., Mu, L., Huang, J., Yu, S., Chen, B. and Yin, J. (2005) An Initial Investigation of the Association between the SARS Outbreak and Weather: With the View of the Environmental Temperature and Its Variation. Journal of Epidemiology \& Community Health, 59, 186-192. https://doi.org/10.1136/jech.2004.020180

[25] Liu, J., Hua, D., Zhang, Y., Japip, S. and Chung, T.S. (2018) Precise Molecular Sieving Architectures with Janus Pathways for Both Polar and Nonpolar Molecules. Advanced Materials, 30, Article ID: 1705933. https://doi.org/10.1002/adma.201705933

[26] National Agency for Health Security of Guinea (2020) Report of April 3rd, 2020. https://anss-guinee.org/welcome/document

[27] Worldometers (2020) Reported Cases and Deaths by Country, Territory, or Conveyance for June 27, 2020. https://www.worldometers.info/coronavirus/\#countries

[28] Loua, R.T., Bencherif, H., Mbatha, N., Bègue, N., Hauchecorne, A., Bamba, Z. and Sivakumar, V. (2019) Study on Temporal Variations of Surface Temperature and Rainfall at Conakry Airport, Guinea: 1960-2016. Climate, 7, Article No. 93. https://doi.org/10.3390/cli7070093

[29] European Centre for Disease Prevention and Control (2020) Communicable Disease Threats Report, 19-25 April 2020, Week 17. European Centre for Disease Prevention and Control, Solna Municipality.

https://www.ecdc.europa.eu/en/publications-data/communicable-disease-threats-re port-19-25-april-2020-week-17

[30] Sedgwick, P. (2012) Pearson's Correlation Coefficient. BMJ, 345, e4483. https://doi.org/10.1136/bmj.e4483

[31] Akoglu, H. (2018) User's Guide to Correlation Coefficients. Turkish Journal of Emergency Medicine, 18, 91-93. https://doi.org/10.1016/j.tjem.2018.08.001

[32] Cohen, J. (1992) Statistical Power Analysis. Current Directions in Psychological Science, 1, 98-101. https://doi.org/10.1111/1467-8721.ep10768783

[33] Sajadi, M.M., Habibzadeh, P., Vintzileos, A., Shokouhi, S., Miralles-Wilhelm, F. and Amoroso, A. (2020) Temperature and Latitude Analysis to Predict Potential Spread and Seasonality for COVID-19. Available at SSRN 3550308. https://doi.org/10.2139/ssrn.3550308

[34] Wang, Y., Wang, Y., Chen, Y. and Qin, Q. (2020) Unique Epidemiological and Clinical Features of the Emerging 2019 Novel Coronavirus Pneumonia (COVID-19) Implicate Special Control Measures. Journal of Medical Virology, 92, 568-576. https://doi.org/10.1002/jmv.25748

[35] He, Z., Chin, Y., Huang, J., He, Y., Akinwunmi, B.O., Yu, S., et al. (2020) Meteorological Factors and Domestic New Cases of Coronavirus Disease (COVID-19) in nine Asian Cities: A Time-Series Analysis. MedRxiv. 
https://doi.org/10.1101/2020.04.15.20066613

[36] Qi, H., Xiao, S., Shi, R., Ward, M.P., Chen, Y., Tu, W., et al. (2020) COVID-19 Transmission in Mainland China Is Associated with Temperature and Humidity: A Time-Series Analysis. Science of the Total Environment, 728, Article ID: 138778. https://doi.org/10.1016/j.scitotenv.2020.138778

[37] Prata, D.N., Rodrigues, W. and Bermejo, P.H. (2020) Temperature Significantly Changes COVID-19 Transmission in (Sub) Tropical Cities of Brazil. Science of the Total Environment, 729, Article ID: 138862. https://doi.org/10.1016/j.scitotenv.2020.138862

[38] Şahin, M. (2020) Impact of Weather on COVID-19 Pandemic in Turkey. Science of the Total Environment, 728, Article ID: 138810. https://doi.org/10.1016/j.scitotenv.2020.138810

[39] Poole, L. (2020) Seasonal Influences on the Spread of SARS-CoV-2 (COVID19), Causality, and Forecastabililty (3-15-2020). https://doi.org/10.2139/ssrn.3554746

[40] Shi, S., Qin, M., Shen, B., Cai, Y., Liu, T., Yang, F., et al. (2020) Association of Cardiac Injury with Mortality in Hospitalized Patients with COVID-19 in Wuhan, China. JAMA Cardiology, 5, 802-810. https://doi.org/10.1001/jamacardio.2020.0950

[41] Auler, A.C., Cássaro, F.A.M., da Silva, V.O. and Pires, L.F. (2020) Evidence That High Temperatures and Intermediate Relative Humidity Might Favor the Spread of COVID-19 in Tropical Climate: A Case Study for the Most Affected Brazilian Cities. Science of the Total Environment, 729, Article ID: 139090. https://doi.org/10.1016/j.scitotenv.2020.139090

[42] Ahmadi, M., Sharifi, A., Dorosti, S., Ghoushchi, S.J. and Ghanbari, N. (2020) Investigation of Effective Climatology Parameters on COVID-19 Outbreak in Iran. Science of the Total Environment, 729, Article ID: 138705. https://doi.org/10.1016/j.scitotenv.2020.138705

[43] Bashir, M.F., Ma, B., Komal, B., Bashir, M.A., Tan, D. and Bashir, M. (2020) Correlation between Climate Indicators and COVID-19 Pandemic in New York, USA. Science of the Total Environment, 728, Article ID: 138835. https://doi.org/10.1016/j.scitotenv.2020.138835

[44] Liu, J., Zhou, J., Yao, J., Zhang, X., Li, L., Xu, X., et al. (2020) Impact of Meteorological Factors on the COVID-19 Transmission: A Multi-City Study in China. Science of the Total Environment, 726, Article ID: 138513. https://doi.org/10.1016/j.scitotenv.2020.138513

[45] Tan, L., Wang, Q., Zhang, D., Ding, J., Huang, Q., Tang, Y.Q., et al. (2020) Lymphopenia Predicts Disease Severity of COVID-19: A Descriptive and Predictive Study. Signal Transduction and Targeted Therapy, 5, Article No. 61. https://doi.org/10.1038/s41392-020-0159-1

[46] Lin, K., Fong, D.Y.T., Zhu, B. and Karlberg, J. (2006) Environmental Factors on the SARS Epidemic: Air Temperature, Passage of Time and Multiplicative Effect of Hospital Infection. Epidemiology \& Infection, 134, 223-230.

https://doi.org/10.1017/S0950268805005054

[47] Park, J.E., Son, W.S., Ryu, Y., Choi, S.B., Kwon, O. and Ahn, I. (2020) Effects of Temperature, Humidity, and Diurnal Temperature Range on Influenza Incidence in a Temperate Region. Influenza and Other Respiratory Viruses, 14, 11-18. https://doi.org/10.1111/irv.12682

[48] Tosepu, R., Gunawan, J., Effendy, D.S., Lestari, H., Bahar, H. and Asfian, P. (2020) Correlation between Weather and COVID-19 Pandemic in Jakarta, Indonesia. Science of the Total Environment, 725, Article ID: 138436. 
https://doi.org/10.1016/j.scitotenv.2020.138436

[49] Yao, Y., Pan, J., Liu, Z., Meng, X., Wang, W., Kan, H. and Wang, W. (2020) No Association of COVID-19 Transmission with Temperature or UV Radiation in Chinese Cities. European Respiratory Journal, 55, 2000517.

https://doi.org/10.1183/13993003.00517-2020

[50] Lin, J., Huang, W., Wen, M., Li, D., Ma, S., Hua, J. and Zhang, Q. (2020) Containing the Spread of Coronavirus Disease 2019 (COVID-19): Meteorological Factors and Control Strategies. Science of the Total Environment, 744, Article ID: 140935.

https://doi.org/10.1016/j.scitotenv.2020.140935 